\title{
Establishment of MilletDB: TNAU Released Millet Varieties with their Morphological Traits
}

\author{
Dhivya A B \\ Department of Plant \\ Molecular Biology \\ and Bioinformatics, \\ Center for Plant \\ Molecular Biology \\ and Biotechnology, \\ Tamil Nadu \\ Agricultural \\ University, \\ Coimbatore-641003, \\ Tamilnadu, India
}

\author{
Subashini S \\ Department of Plant \\ Molecular Biology \\ and Bioinformatics, \\ Center for Plant \\ Molecular Biology \\ and Biotechnology, \\ Tamil Nadu \\ Agricultural \\ University, \\ Coimbatore-641003, \\ Tamilnadu, India
}

\author{
Chandrababu $\mathrm{R}$ \\ Department of Plant \\ Molecular Biology \\ and Bioinformatics, \\ Center for Plant \\ Molecular Biology \\ and Biotechnology, \\ Tamil Nadu \\ Agricultural \\ University, \\ Coimbatore-641003, \\ Tamilnadu, India
}

\author{
Ramalingam J \\ Department of Plant \\ Molecular Biology \\ and Bioinformatics, \\ Center for Plant \\ Molecular Biology \\ and Biotechnology, \\ Tamil Nadu \\ Agricultural \\ University, \\ Coimbatore-641003, \\ Tamilnadu, India
}

\begin{abstract}
Millets are annual grasses and grow well under the marginal conditions of soil fertility and moisture, which provide staple food for millions of people. Millets have strong, deep rooting systems and short life cycles. Breeding research in millets, habitually engages different species, cultivars, and varieties. This makes an immense challenge to maintain the different varieties and their identification characters. On account of this fact, the MilletDB clearly brings out the variations of different morphological traits of the TNAU released millet varieties and germplasm information about the pearl millet. MilletDB is an Internet-accessible database, which is designed by using the front-end language PHP and back-end as MySQL and is equipped with extensive search options. It is a user-friendly database and made publicly available, to improve the research and development of millet crops by making the wealth of available millet varieties.
\end{abstract}

\section{Keywords}

Millet, morphological traits, PHP, MySQL, varieties, Database

\section{INTRODUCTION}

Millets are one of the oldest of cultivated cereal crops. The terminology "millets" which includes a group of highly variable grass crops, whose seeds/grains are harvested for both food and/or feed. It is the most widely grown around the world, and it is essentially grown in the areas of arid and semiarid regions. Millet is composed primarily $(60-80$ per cent) of carbohydrates. Millets are amazing in their nutrition content, has a sweet nutty flavor, and the nutritional value of millets is slightly higher in the contents of protein and minerals than cereals (Gopalan et al., 2002). Mostly millet grains do not contain gluten (Leder, 2004), which usualy causes some forms of allergies or coeliac diseases. The ancient grain, millet, is a staple grain in many countries of Asia and Africa and an alternative to rice. Millets are particularly high in minerals like iron, magnesium, phosphorous and potassium. Each of the millets is three to five times nutritionally better than widely promoted rice and wheat. India leads the largest producer of millets in the world. In 2007, India produced 10,610,000 tonnes of Millets, becoming the highest producer around the globe. In recent years, the regions under these crops are not much amplified.
The various millet species are subdivided into major and minor millets (Rakshit et al., 2013). The Major millet are Pearl millet (Pennisetum glaucum), Maize (Zea mays) and Sorghum (Sorghum bicolor). Pearl millet (Pennisetum glaucum (L.) R. Br.) is a warm season crop and it is more tolerant of sandy and acidic soils than any other summer grain crops. The stalks of Pearl millet range from 5 to 10 feet (1.5 to 3 metres) tall and about 1 inch $(2.54 \mathrm{~cm})$ thick. It is a staple crop for populations living in arid and semi-arid climates (Rai et al., 2009). Maize is the third most important crop in India after rice and wheat. It is a short-term (80-95 days) crop and it conveniently fits into a wide range of crop rotations. Its ear contains the presence of a terminal, fertile, and aborted, lateral flower in each of the paired spike lets (Bonnett et al., 1954). Sorghum (Sorghum bicolor) is a staple cereal food and forage crop grown primarily in semiarid regions and it can stand with prolonged droughts (Nagaraja Reddy et al., 2008).

The minor millets are small seeded annual grasses (Rachie, 1975) which includes Proso millet (Panicum miliaceum L.), Little millet (Panicum sumatrense), Foxtail millet (Setaria italica L.), Barnyard millet (Echinochloa frumentaceae L.), Kodo millet (Paspalum scrobiculatum), Finger millet (Eleusine coracana) (Seetharam et al., 1998). Proso millet (Panicum miliaceum) is an annual grass and is well suited to dry climates with short growing seasons. It has also been called common millet, hog millet, broom corn, yellow hog, hershey, and white millet (Baltensperger et al., 1996). Little millet (Panicum miliare), exhibit diversified use as food, feed and fodder, since it is nutritious, healthy and versatile food and a worthy addition to one's diet (Roopa et al., 2013). Foxtail millet (Setaria italica) has a short growing season and this makes it suited to the farming conditions of the semi arid climate, which belongs to the grass family of Poaceae (Obidiegwu et al., 2013). It is well known for human food among old world species (Austin, 2006). Barnyard millet (Echinochloa frumentacea) is one of the fastest growing minor millets, which is a temperate zone crop suited in low and moderate rainfall ranging between 500 to $700 \mathrm{~mm}$. Barnyard millet is one of the important millet crops, because of their high dietary fibre content, which is recognized for its hypocholestremic and hypoglycemic effects, apart from contributing to high satiety value (Veena et al., 2005). Kodo millet (Paspalum scrobiculatum) is one of the hardiest crops grown, which is the major source of protein and minerals in 
the daily diets of tribal and weaker section living in remote rural areas of India (Neelam et al., 2013). In India, Finger millet (Eleusine coracana) commonly known as Ragi is an important cereal which needs highest area for cultivation . Finger Millet has the highest amount of calcium and potassium (Verma and Patel, 2013).

The varietal characters and morphological parameters information of millet variety is essential for recognition of varieties to the plant breeders, for selection of suitable varieties for different farm conditions to the farmers and also for choosing parents of a variety with desirable characters to the agricultural researchers. Consequently, data resources concerning these characters and parameters required to be assembled properly to build a new database and accordingly this information will be generated as required by diverse endusers in a well-organized manner. With the advancement of the computer technologies, we can retrieve, organize, analyze and can store of large volume of data. High speed stored information has become effortless and reasonable and has led to a qualitative change to perform an effective biological research.

The volume of information available to the biological community is continuously increasing and diversifying. Whereas the broad-spectrum databases such as GenBank are playing an important role in the storage of information, but these databases are not expected to deal with the specific requirements of particular fields. There is a necessity for specific databases to congregate the individual requirements of the diverse research communities, to a particular subject, and to provide in-depth of information. As well as, this database is being designed in order to retrieve the accurate information about millets and its varieties released from TNAU. For this reason the database is essential and plays an indispensable role in improving the research activity. These databases systematize the data for easy access and manipulation.

The database system is designed to be user - friendly with the use of different Graphical User Interface (GUI) programs. This allows the user to give the choice for variety selection, character selection and manual comparison of varieties and characters and can get the required information in the form of tables and color pictures by just using a mouse with minimal keyboard operations.

\section{MATERIAL AND METHODS}

The Millet database provides information about the morphological characteristics of TNAU released major and minor millets. It holds the varietal information for different research station such as Coimbatore, Paiyur, Aruppukottai, Bhavanisagar, Kovilpatti, Pudukkottai located in the states of Tamilnadu. These varieties are defined by several parameters. Some of the common parameters are Name, Parentage, Duration, Season, Area of adoption, Yield, Habit, Pest resistance, Disease resistance, Protein content (Lagler et al., 2005).

The millet database probably have major and minor millets and is developed using MySQL open source database management system (Vikram Vaswani, 2004) as the backend language. At the heart of the database there are 9 tables for data storage and selection. The main way the user communicates with the database is through predefined form, and the milletDB form is the main entry point, for data entry and retrieval.
The web page is developed using the front end language PHP (Hypertext Pre Processor) (Steven Holzner, 2008) and is embedded into HTML. The layout of the search pages in milletDB is based on those in the interface and has been generated using the PHP programming language. The script allows the client to specify the query parameters and retrieve data for the relavant attributes from the primary database.

The MySQL tables are stored in the databases of the Webmin server. The Database Administrator has the privilege to add new varieties in the backend server. The user interface is built with HTML (Hyper Text Markup Language) and CSS (Cascading Style Sheet) (Jon Duckett, 2011).

The appearance of the result pages has been personalized to be more user friendly and characteristic biological information can be retrieved from specific database queries. Based upon the request from the user, the webpage search and fetch the information from the corresponding table in the database and displayed the requested information in the webpage. The millet database display results on individual pages, and hyperlinks in pages, allow the user to navigate easily between pages. The interface was completely designed and programmed in-house and will therefore, be easier and more efficient to maintain.

The user can easily examine the varieties in the resulting pages just by clicking the search button in the main page of each millet. Clicking on a variety name results in an HTML table, along with their corresponding data. A query window for character search is provided on every millet page.

\section{1Flow of Data}

Data flow diagram is as shown in the Figure 1

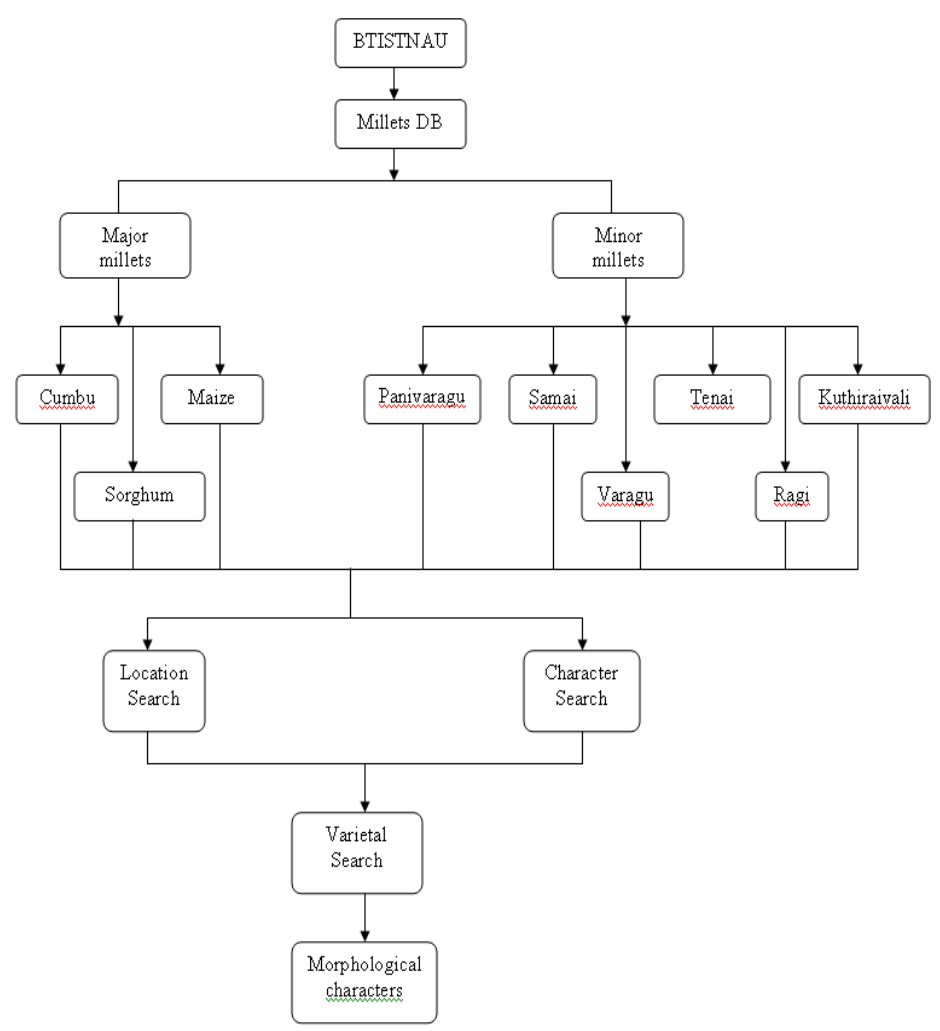

Fig 1: Flowchart representing Millet database 


\subsection{Utility}

The basic intention of this database is to provide breeders, students and researchers to easily access valuable information about the morphological characters of major and minor millet which was released in the TNAU and it is hosted in the BTISTNAU Domain. MilletDB provides a central, comprehensive, well-validated resource where researchers can access integrated data of many types, by biological experts and morphological information. This database is provided with a user friendly environment and it supports keyword searching. Users are allowed to search their corresponding millet varieties in the database using their own words and phrases via keyword searching. Keywords in the search are not case sensitive so it makes databases accessible, safe and easy to use. Pearl millet database alone provides a genotype search in which the user can search and find information about the evaluated germplasm. The database will be updated routinely for inclusion of any new millet varieties released in the TNAU.

\section{ACKNOWLEDGMENTS}

This work is supported by the Department of Biotechnology, Government of India under Biotechnology Information System (BTIS) scheme.

\section{REFERENCES}

[1] Austin,D.F. 2006. Foxtail millets (Setaria: Poaceae) abandoned food in two hemispheres. Econ Bot, 60, 143 158 .

[2] Bonnett,O.T. 1954. The Inflorescences of Maize. Science, 120 (3107), 77-87.

[3] Baltensperger,D.D. 1996. Foxtail and Proso Millet. J. Janick (ed.), Progress in new crops, 182-190.

[4] Gopalan,C. et al. 2002. Nutritive value of Indian Foods. National Institute of Nutrition $\quad$ (ICMR), 47.

[5] Jon Duckett. 2011. HTML and CSS: Design and Build Websites, first ed. John Wiley \& Sons.

[6] Leder,I. et al. 2004. Sorghum and millets. Cultivated plants, primarily as food sources. Füleky G (ed.), Eolss Publishers, Oxford ,UK.

[7] Lagler,R. et al. 2005. Morphological and molecular analysis of common millet (P. miliaceum) cultivars compared to an aDNA sample from the 15th century (Hungary). Euphytica. 146, 77-85.

[8] Neelam,Y. et al. 2013. Evaluation of hypoglycemic properties of kodo millet based food products in healthy subjects. Iosr Journal Of Pharmacy, 3(2), 14 - 20.

[9] Nagaraja Reddy,R. et al. 2008. Inheritance of morphological characters in sorghum. International Crops Research Institute for the Semi-Arid Tropics.

[10] Obidiegwu,O.N. et al. 2013. Development of SSR for foxtail millet (Setaria italica (L.) P. Beauv.) and its utility in genetic discrimination of a core set Genes Genom. 35 , $609-615$

[11] Rakshit,S. et al. 2013. Global consultation on millets promotion for health \& nutritional security. Society for Millets Research, ISBN 81-89335-47-2.

[12] Rai,K.N. et al. 2009. Morphological characteristics of ICRISAT-bred pearl millet hybrid seed parents. International Crops Research Institute for the Semi-Arid Tropics, 176.

[13] Roopa,U. et al. 2013. Physico-chemical and functional properties of little millet genotypes. Karnataka J. Agric. Sci, 26 (4), 539-542.

[14] Rachie,K.O. 1975. The Millets: Importance, utilization and outlook. International Crop Research Institute for the Semi-arid Tropics,1-2.

[15] Steven Holzner. 2008. PHP: The Complete Reference, first ed. McGraw-Hill Osborne.

[16] Seetharam,A. 1998. Small millets research: achievements during 1947-97, Vol 68.

[17] Veena,S. et al. 2005. Physico-Chemical and Nutritional Studies in Barnyard Millet. Karnataka J. Agric. Sci, 18(1), 101- 105.

[18] Verma,V. and Patel,S. 2013. Value added products from nutri-cereals: Finger millet (Eleusine coracana). Emir. J. Food Agric, 25 (3), 169-176.

[19] Vikram Vaswani. 2004. Mysql: The Complete Reference 1st Edition. Tata Mcgraw Hill Education Private Limited. 